\title{
A Complicated Urinary Bladder Diverticulum Herniation- A Case Report
}

\author{
Parajuli $S^{1}$, Sharma $P^{1}$, Gyawali $\mathbf{M}^{1}$, Lalchan $S^{1}$, KC S ${ }^{1}$, Acharya GB ${ }^{2}$, \\ Thapa $\mathbf{N}^{2}$, Tiwari PK ${ }^{1}$, Poudel $\mathbf{R}^{1}$ \\ ${ }^{1}$ Department of Radiology and Imaging, Manipal Teaching Hospital, Pokhara, Nepal \\ ${ }^{2}$ Department of Urology, Manipal Teaching Hospital, Pokhara, Nepal
}

Received: February 10, 2018

Accepted: March 10, 2018

Published: June 30, 2018

Cite this paper:

Parajuli S, Sharma P, Gyawali M et al. A Complicated Urinary Bladder Diverticulum Herniation-A Case Report. Nepalese Journal of Radiology 2018;8(11):41-43.http://dx.doi.org/10.3126/njr.v8i1.20456

\begin{abstract}
Urinary bladder diverticulum presenting as an inguinal hernia is an uncommon condition found in about $1-5 \%$ of inguinal hernia. Long standing increase of the intravesical pressure resulting from urinary bladder outlet obstruction can cause both secondary bladder diverticula and groin hernias. We present a case of urinary bladder diverticulum herniating through the left inguinal canal, which was confirmed by micturating cystourethrogram. Although these conditions are usually, diagnosed intraoperatively, radiological diagnosis still holds its utmost importance to improve the overall management.
\end{abstract}

Keywords: Bladder diverticulum; Cystography; Hernia, inguinal

\section{INTRODUCTION}

Inguinal bladder is an uncommon condition found in $1-5 \%$ of inguinal hernias $(\mathrm{IH}) .{ }^{1,2}$ It can be due to long standing increase of the intravesical pressure which gives rise to secondary bladder diverticulum and hernia. The commonest cause of rise of intravesical pressure is bladder outlet obstruction. In males, most common cause for bladder outlet obstruction (BOO) is benign prostatic hyperplasia $(\mathrm{BPH}){ }^{3} \quad$ A careful clinical suspicion and judicial radiological assessment is a must for proper diagnosis of inguinal bladder hernia.

Correspondence to: Dr. Santwana Parajuli

Resident, Department of Radiology

Manipal Teaching Hospital, Pokhara, Nepal

Email: parajulisantwana@gmail.com
The following case report deals with a case of 63 years male who presented with lower 
urinary tract symptoms (LUTS) and left inguinal swelling. He was diagnosed BPH with inguinal hernia clinically and was asked for micturating cystourethrogram / retrograde urethrogram (MCU/RGU) for further evaluation.

\section{CASE REPORT}

A-63 year old male presented to Department of Urosurgery outpatient department (OPD) with chief complaints of left inguinal swelling and difficulties in micturition including incomplete voiding. The swelling would reduce when compressed with increased urinary flow. During clinical examination, there was a painless irreducible swelling seen in left inguinal region with measuring around $7 \times 5 \mathrm{cms}$. On ultrasound, prostate gland was enlarged in size (63.0 gms) with left inguinal hernia. Micturating cystourethrogram demonstrated small globular outpouching of the left lateral wall of the urinary bladder. On further instillation of the contrast, the contrast filled outpouching was found to herniate into the left inguinal region (Fig 1, Fig 2). The diverticulum was decreased on size with passage of urine and finally collapsed on external pressurized emptying with no obvious reflux of contrast into ureter. Urinary bladder demonstrated minimal trabeculations.

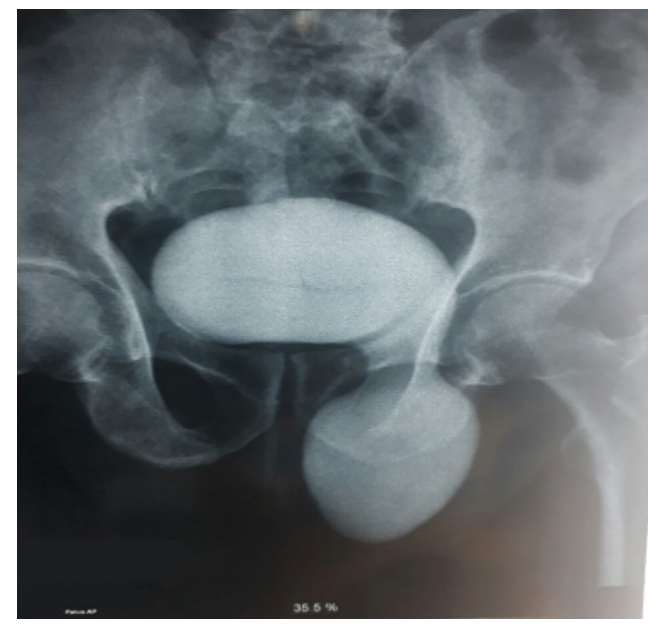

Figure 1.

\section{DISCUSSION}

Herniation of the urinary bladder is a relatively uncommon but not a rare condition. ${ }^{1}$ It occurs when the urinary bladder or ureter herniates into the inguinal canal. Herniation can reach to scrotal sac or sometimes through femoral canal, which is even very rare. Bladder herniation occurs in an acquired direct inguinal hernia with the bladder pulled into the hernia, together with a sheath of peritoneum, which forms a sac like structure. Some factors are associated with the pathophysiology of bladder herniation, such as chronic urinary obstruction, obesity, elderly population, decreased bladder tone, and weakness of the pelvic musculature. ${ }^{4}$ These hernias have a predilection for the right side. ${ }^{5}$ Different diagnostic modalities may be used. Ultrasound (US) is first, cost effective and most accessible diagnostic modality. It may demonstrate hypoechogenic mass lesion protruding from the bladder through the inguinal canal into scrotum. ${ }^{6}$ Voiding cystourethrography is best diagnostic imaging modality for inguinal bladder hernia. It may reveal dog-ear shaped bladder in the scrotum. Indirect signs are small asymmetric bladder, incomplete visualization of bladder base and lateral displacement of the lower ureter. In typical supine radiographs, they are usually missed. Prone position can improve the

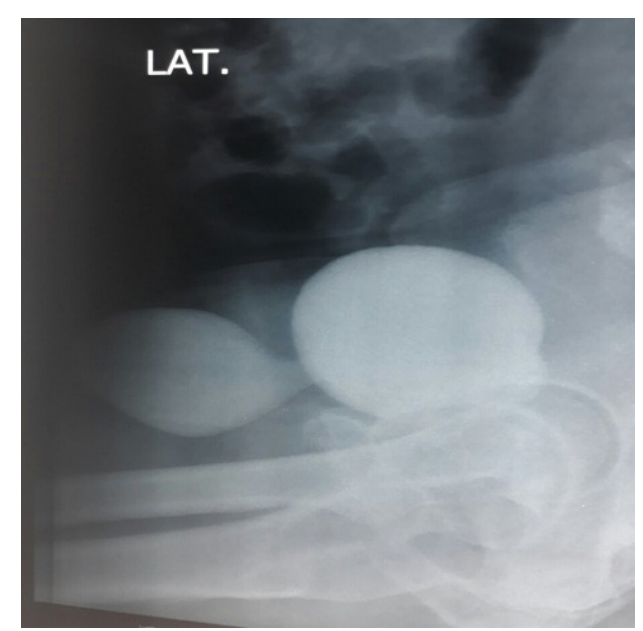

Figure 2.

Figure 1 and 2: Cystogram AP and Lateral views showing contrast filled urinary bladder diverticulum herniating into the left inguinal canal. Arrow pointing herniated diverticulum. 
detection, while erect radiographs can detect $100 \%$ of such hernias. ${ }^{6}$ Pointing of the bladder toward the side of the hernia, i.e. angulation of the bladder base anteroinferiorly, is the CT sign of bladder herniation. Findings in MRI are similar to CT features of bladder hernia, however coronal and sagittal planes can give better outline. Also, relations to adjacent vascular landmarks can be well identified. ${ }^{5}$

\section{CONCLUSION}

Inguinal bladder hernia should be considered in an old male patient presenting with lower urinary tract symptoms and inguinal swelling. Imaging has pivotal role in the diagnosis as well as overall management of these cases.

\section{CONFLICT OF INTEREST}

None

\section{SOURCE OF FUNDING}

None

\section{REFERENCES}

1. Khan A, Beckley I, Dobbins B, Rogawski KM. Laparoscopic repair of massive inguinal hernia containing the urinary bladder. Urol An 2014;6(2):159162. $\quad$ https://doi.org/10.4103/0974$\underline{7796.130654}$

2. Madani AH, Nikouei HM, Aval HB, Enshaei A, Asadollahzade A, Esmaeili S. Scrotal herniation of bladder: a case report. Iran J Med Sci 2013;38(1):62-64. Available from: https://www.ncbi.nlm. nih.gov/pmc/articles/PMC3642947/ [Accessed 6th Nov 2017].

3. Choi J, Shendrik I, Peacocke M et al. Expression of senescence-associated beta-galactosidase in enlarged prostates from men with benign prostatic hyperplasia. Urology 2000;56:160-166. https://doi.org/10.1016/S0090$\underline{\text { 4295(00)00538-0 }}$
4. Moufid K, Touiti D, Mohamed L. Inguinal Bladder hernia: four case analyses. Rev Urol 2013;15(1):32-36. Available from: https://www. ncbi.nlm.nih.gov/pmc/articles/ PMC3651540/ [Accessed 6th Nov 2017].

5. Bacigalupo LE, Bertolotto M, Barbiera F et al. Imaging of urinary bladder hernias. AJR Am J Roentgenol 2005;184(2):546-551. ht tps://doi .org/10.2214/ ajr.184.2.01840546

6. Kraft KH, Sweeney S, Fink AS, Ritenour CWM, Issa MM. Inguinoscrotal bladder hernias: report of a series and review of the literature. Can Urol Assoc J 2008;2(6):619-623. https://doi.org/10.5489/cuaj.980 